\title{
Literatura e cinema de horror/terror para o ensino de língua inglesa no Ensino Médio
}

\section{Horror/terror literature and cinema in the English language teaching in Secondary School}

Thiago de Freitas Santos ${ }^{1}$

\begin{abstract}
Resumo
Esta narrativa de ensino, voltada para o ensino-aprendizagem de língua inglesa, relata o desenvolvimento do projeto que tem em seu cerne a ficção de horror/terror na literatura e no cinema. O público-alvo foram duas turmas de $2^{\circ}$ ano do Ensino Médio do curso integrado de Guia de Turismo, do Instituto Federal da Bahia - Campus Valença. Ao longo do projeto, tivemos como objetivos o estudo, a leitura e as discussões de livros clássicos da literatura gótica e do cinema de horror/terror. Esse projeto tem sido empregado há três anos e tem apresentado resultados que incluem a participação ativa das turmas, por intermédio de atividades dinâmicas e criativas, desenvolvidas no contexto de sala de aula. Tomamos como referência para este estudo as atividades desenvolvidas especificamente no ano letivo de 2019.
\end{abstract}

Palavras-chave: Ensino. Ficção. Horror.

\begin{abstract}
This teaching narrative, focused on teaching the English language, reports the development of the project that has at its core the horror/terror fiction in literature and cinema. The target audience were two classes of the 2nd year of Secondary School in the integrated course of Guia de Turismo, at the Federal Institute of Bahia - Campus Valença. Throughout the project, we had as main objectives the study, reading and discussions of classical books of the gothic literature and of the horror/terror cinema. This project has been developed for three years and has shown results that include the active participation of the classes involved, through dynamic and creative activities, developed in the classroom context. We take as a study reference the activities developed specifically in the academic year of 2019.
\end{abstract}

Keywords: Teaching. Fiction. Horror.

\section{Apresentação}

Entendemos o uso da literatura e de outras artes como uma ferramenta didática importante no processo de ensino-aprendizagem de uma língua estrangeira, pois nos permite explorar uma variedade de gêneros textuais, temas e métodos no desenvolvimento das atividades acadêmicas. Nesse sentido, esta narrativa pretende apresentar a utilização e os desdobramentos do gênero ficcional de horror/terror nas relações linguísticas e culturais em sala de aula. Ao longo do texto, percorreremos obras provenientes dos países Inglaterra e Estados Unidos, origem de muitos clássicos da literatura e do cinema do estilo, ao exemplo de Horace Walpole, Mary Shelley, Edgar Allan Poe e do contemporâneo Stephen King, cuja obra tem sido amplamente adaptada para o cinema, em grandes produções, como os mais atuais It e 1922, ambos de 2017.

\footnotetext{
1 Mestre em Literatura. Instituto Federal de Educação, Ciência e Tecnologia da Bahia (IFBA) - Campus Valença, Valença, Bahia, Brasil. E-mail: thgdefreitas@gmail.com
} 
Para compreendermos a amplitude que o tema selecionado pode nos proporcionar, tomemos como referência o que diz Vera Lúcia Paiva (2012), em Ensino de língua inglesa no ensino médio: teoria e prática:

"A literatura dá ao aprendiz acesso à produção cultural em outra língua e proporciona experiência estética. Além de despertar o prazer estético, o texto literário contribui para aumentar a exposição ao idioma e o desenvolvimento do senso crítico. Por meio da ficção, podemos entender melhor a natureza humana e as relações sociais, assim como estabelecer conexões entre ficção e fatos da vida real" (p. 84).

Em vista disso, percebemos que o uso da literatura, além de colaborar com a formação do leitor, possibilita integração com a cultura literária. Com o emprego de gêneros textuais, é possível abordar uma diversidade de tópicos, em um leque que vai desde a utilização das estratégias de leitura, o estudo de gramática, construção de vocabulário, pronúncia, passando pelo contato com assuntos culturais, que podem ser de diferentes épocas e estilos. Esse tipo de abordagem, por intermédio de uma seleção de textos de fiç̧ão, nos permite construir um diálogo entre a sala de aula e os países de língua inglesa.

Desse modo, tendo como ponto de partida a leitura e a análise de produções literárias e cinematográficas, podemos integrar as quatro habilidades da língua - escutar, falar, ler e escrever -, em prol de um projeto de multiletramento e em acordo com as Orientações Curriculares para o Ensino Médio (OCEM), na qual o conceito de leitura contempla as modalidades visuais, por meio das mídias e do cinema, além de ser multicultural e crítica.

Ainda sobre o uso de gêneros literários no ensino de língua inglesa, Margaret Corchs (2008), em dissertação pela Universidade Estadual do Ceará, argumenta que a literatura pode despertar o interesse dos alunos, uma vez que engloba uma variedade de elementos desconhecidos por muitos, como linguagem poética, estilos de escrita e questões culturais. Também podemos pensar que, por sua inerente subjetividade, no sentido de mexer com as emoções e com abstrações, a literatura proporciona uma visão mais ampla e rica de informações. Dessa forma, podemos usar a criatividade em atividades interessantes e diferenciadas que proporcionam desenvolvimento no aprendizado do idioma.

De modo geral, portanto, concluímos que o texto literário funciona como um importante instrumento para melhorar as habilidades linguísticas dos alunos, pois contribui para a compreensão de diferenças culturais e possibilita a ampliação de oportunidades para o crescimento pessoal e para 0 aprendizado do idioma. Por essa razão, esperamos que o projeto de ensino aqui pormenorizado, sobretudo por conta da utilização dos variados gêneros textuais, como a poesia, os textos informativos, cinema e outros, possa desafiar e enriquecer tanto o professor como também os alunos.

A narrativa de ensino aqui descrita foi baseada em encontros semanais com duas turmas de segundo ano do Ensino Médio, do curso integrado de Guia de Turismo, no Instituto Federal da Bahia, Campus Valença, durante uma das quatro unidades do ano letivo. No total foram 44 alunos, divididos em 
uma turma com 24 e outra com 20 estudantes, com idades entre 15 e 18 anos. A temática principal da unidade girou em torno da ficção de horror/terror na literatura e no cinema e envolveu atividades dinâmicas que, na nossa percepção, despertaram um enorme interesse nas turmas envolvidas, uma vez que lidam com nossos mais elementares sentidos, como o medo do desconhecido, da morte e do sobrenatural. Quando crianças, temos medo da escuridão que paira sobre uma porta entreaberta ou do monstro que acreditamos estar debaixo da cama. Assim, os terrores da imaginação correm soltos nessa idade e evidenciam percepções que parecem estar fora da explicação racional, como por exemplo, a sensação de uma presença ameaçadora nas sombras logo atrás de nós que pode ou não desaparecer se pudermos reunir a coragem de nos virarmos e encará-la. Ao longo dos anos, como adultos, nossos medos se tornam mais sofisticados, mais fundamentados em eventos mundanos.

Diante do exposto, pretendemos levantar algumas reflexões sobre como promover a ficção literária em sala de aula, como despertar o interesse dos alunos e como fazer com que gostem de ler e saibam analisar aspectos de determinadas obras. Ademais, aspiramos trazer sugestões e discutir sobre as dificuldades de trabalhar o gênero literário no ensino-aprendizagem de língua inglesa no Ensino Médio, tendo em vista que, como observa Rildo Cosson (2019), em Letramento literário: teoria e prática, "0 ensino da literatura limita-se à literatura brasileira, ou melhor, à história da literatura brasileira [...], quase como apenas uma cronologia literária, em uma sucessão dicotômica entre estilos de época, cânone e dados biográficos dos autores." (COSSON, 2019, p. 21)

Nessa perspectiva, os modos de apresentar a literatura ao público não cativam, sobretudo porque vivemos em uma era tecnológica, na qual as redes sociais e os jogos de videogame bem elaborados e dinâmicos tomam o tempo das pessoas, especialmente dos adolescentes. Por isso, acreditamos que a escolha do tema para a unidade abrange essas carências, porque proporciona trabalharmos com uma variedade de formas de linguagem e atividades culturais que envolvem, além do texto literário, a possibilidade de utilizarmos jogos eletrônicos, séries de entretenimento e filmes. 


\section{Contextualização do horror/terror na literatura e no cinema}

O texto selecionado para a unidade, The evolution of horror in fiction: a brief guide, de Felipe Wasserstein $(2017)^{2}$, é a principal referência teórica para o desenvolvimento do projeto, no sentido em que apresenta um panorama conciso, com linguagem jornalística, no qual pondera sobre os principais temas, definições e autores que moldaram e contribuíram para a consolidação do gênero horror/terror, desde o século XVIII.

No início, o autor discute as definições do gênero por meio de referências como J.A Cuddon, Douglas Winter e do livro The philosophy of horror, organizado por Richard Fahy. Segundo as definições abordadas no texto, o horror/terror pode ser definido como um tipo de fiç̧ão que choca o leitor/espectador e que pode induzir aos sentimentos de repulsa e aversão, além de ter como característica um forte apelo à emoção e ao visceral. Nesse sentido, também pode ser visto sob o signo de que o leitor tem sensações semelhantes às vividas pelas personagens. Por essas razões, a ficção de horror/terror está associada aos maiores medos do homem e funciona como uma espécie de metáfora para tratar esses assuntos e alguns outros tabus.

Na sequência do guia, Wasserstein (2017) apresenta, em ordem cronológica, escritores e obras precursores do romance gótico. A primeira delas, O castelo de Otranto (1764), de Horace Walpole, é considerada a obra originária do gênero e traz elementos que ainda hoje permeiam e são utilizados para compor uma história de horror, como por exemplo, ambientação medieval, castelos assombrados e mortos que voltam à vida. Em pleno lluminismo, Walpole preferiu atemorizar seus leitores, em uma época em que o racionalismo procurava jogar luz nas "trevas" e o realismo dava o tom da maioria das obras literárias. A partir dessa publicação, outras narrativas similares surgiram e são marcantes para período, como Os mistérios de Udolpho (1794), de Ann Radcliffe e O monge (1796), de Matthew Gregory Lewis.

Segundo Maurício César Mennon (2008), a literatura gótica produzida a partir do século XVIII na Inglaterra apresenta como características cenários ambientados em castelos e mosteiros, donzelas em perigo, vilões cruéis e a presença do sobrenatural. Esse tipo de literatura ganhou espaço e se solidificou como uma das categorias mais lidas da época. Ainda segundo Mennon (2008), a crítica especializada classificava o gênero gótico como inferior e que visava fins comerciais. Além disso, funcionou como uma reação aos árcades e neoclássicos, que tentavam compreender o mundo de modo racional, negando aspectos ligados ao transcendental. Em pleno século das luzes, o autor complementa que a literatura

20 texto pode ser acessado pelo link http://thecircular.org/evolution-horror-fiction-brief-guide/, que pertence ao site de jornalismo online da Griffit Gollege Dublin.

LínguaTec, Instituto Federal de Educação, Ciência e Tecnologia do Rio Grande do Sul, Bento Gonçalves 
gótica teve um papel de retomar a temática do sagrado em um momento em que se negava a existência de forças sobrenaturais.

Ainda de acordo com Wasserstein (2017), durante o século XIX a ficção de horror deu uma guinada para temas como ciência e doenças mentais. As narrativas passaram a incorporar aspectos mais complexos, sobre conflitos do eu interior e sobre decadência social e moral. O período é marcado pelos influentes livros e personagens de Mary Shelley, Frankenstein (1818); pela poesia e prosa de Edgar Allan Poe; pela obra de Robert Louis Stevenson, sobretudo com O médico e o monstro (1886); de Bram Stocker, com Drácula (1897); e da produção literária de Oscar Wilde. Eles foram responsáveis por introduzir novos subgêneros como fiç̧ão científica, o gênero de vampiros e de detetives. São nomes influentes, cujos enredos e personagens ainda são fontes de inspiração para as produções ficcionais atuais (filmes, quadrinhos, desenhos de TV e jogos eletrônicos), especialmente porque lidam com temáticas universais e nos possibilitam discutir em sala de aula, para citar alguns exemplos, questões relacionadas à recriação/clonagem do ser humano, exclusão social, transtornos mentais, o sobrenatural. Consequentemente, podemos conceber reflexões que transponham o ensino de língua inglesa e nos levem a dialogar com outros campos do conhecimento.

Desde meados do século XIX, os textos de horror deixaram de ser restritos aos livros e passaram a ser amplamente publicados em revistas e jornais, aumentando a circulação. $O$ conto passou a substituir o romance como principal formato escolhido por escritores. Já no século $X X$, um dos escritores mais importantes de revistas pulp foi H. P. Lovecraft, tendo publicado suas primeiras produções na revista Weirdtales. Sua prosa tratava de temas relacionados a conhecimentos proibidos, culpa herdada e destino. Embora Lovecraft tenha começado a ganhar reconhecimento, apenas postumamente, seu trabalho influenciou muitos escritores modernos, como Stephen King e Clive Barker.

$\mathrm{O}$ autor prossegue ao examinar que 0 século $\mathrm{XX}$, além de produzir mais monstros e narrativas fantásticas, trouxe 0 advento do cinema. De acordo com Wasserstein (2017), durante as décadas de 30 e 40, foi produzida uma grande quantidade de filmes baseados nas personagens e narrativas góticas, como os dois filmes Drácula, ambos de 1931, e Frankenstein, do mesmo ano. Todos produzidos pela Universal Pictures. A segunda metade do século trouxe o advento do gênero slasher, em enredos com assassinos que perseguem suas vítimas com facas e lâminas, como O massacre da serra elétrica (1974), de Tobe Hooper e Halloween (1978), de John Carpenter. Além disso, foram produzidos os seguintes filmes, atualmente considerados clássicos do cinema: $O$ exorcista, escrito por William Peter Blatty em 1971 e dirigido por William Friedkin em 1973; Tubarão (1974), escrito por Peter Benchley e adaptado um ano depois para o cinema na versão de Steven Spielberg; e Entrevista com um vampiro (1976), livro da escritora Anne Rice, adaptado para o cinema em 1994. 
Por fim, 0 autor conclui 0 artigo observando que o horror continua a se expandir para fora do gênero em si. Atualmente é cada vez mais comum encontrar enredos alternativos, como no livro The terror (2007), de Dan Simmons, que envolve ficção e história, ao retratar a expedição perdida de John Franklin, que foi adaptada para a TV em 2018, no filme paródia Orgulho e preconceito e zumbis (2016) e em quadrinhos como The wytches (2014).

Embora 0 artigo de Felipe Wasserstein (2017) seja o principal parâmetro teórico para 0 andamento das aulas da unidade, não ficamos restritos aos conhecimentos apresentados em The evolution of horror in fiction: a brief guide. Assim sendo, acreditamos ser importante abordar outras questões, como o fato de que, apesar de semelhantes, as literaturas de terror e horror possuem particularidades distintas.

Nesse sentido, em busca de organizar as semelhanças e distinções, podemos citar exemplos como Edgar Allan Poe para representante do terror, embora sua obra apresente aspectos entrelaçados e que tornam difícil uma simples classificação. Seus contos envolvem elementos do imaginário sobrenatural, do sombrio e macabro e, muitas vezes, manifestam características da ficção científica, como viagem no tempo e ressurreição. Outro exemplo de terror é Drácula, de Bram Stoker, romance que apresenta uma atmosfera obscura, um castelo isolado e um homem misterioso, em que tudo converge para compor a atmosfera atemorizante. Vivemos a expectativa pelo próximo instante, uma aflição psicológica que distingue o terror como gênero.

Por outro lado, a literatura de horror compreende atributos ligados ao pavor, uma repugnância de natureza física, que retrata monstros, assassinatos, tortura, cadáveres e que choca o leitor/espectador mediante cenas brutais de violência e sangue. Em Franskestein, por exemplo, o horror irrompe quando temos a descrição da criatura, de sua repugnância e do fato de ter sido criado através de um experimento com partes de cadáveres.

De modo geral, podemos dizer que o terror está relacionado ao temor psicológico, ao passo em que o horror ligado ao grotesco e à repulsa. Ou, como ressalta Menon (2008), o terror evoca elementos que expandem os sentidos, enquanto o horror os retraem.

\section{Desenvolvimento}

A narrativa de ensino descrita a seguir ocorreu em nove encontros semanais, perfazendo uma unidade do ano letivo. No desenvolvimento da atividade, levamos em consideração pressupostos e práticas propostas por Rildo Cosson (2019), em Letramento literário: teoria e prática. Desse modo, tomamos como referência a sequência básica sugerida pelo autor, a saber: motivação, introdução, leitura e interpretação. Assim sendo, ainda que não seja algo restrito, a escolha e a explanação do tema, a 
contextualização, o contato e empréstimo de livros clássicos do gênero, as atividades avaliativas, através de teste escrito, apresentação de seminários e a produção de curtas-metragens, além de outros aspectos do planejamento, intencionaram relacionar-se aos conceitos articulados por Cosson (2019).

Segundo 0 autor, a fase de motivação equivale a uma atividade de preparação para que os alunos adentrem no universo a ser trabalhado durante a unidade. Normalmente, essa etapa se dá de forma lúdica, com uma dinâmica relacionada ao conteúdo e tem como objetivo principal estimular a proposta. No caso da ficção de horror/terror, buscamos suscitar com que os estudantes dissessem palavras em inglês relacionadas ao tema, muitas das quais são cognatas. 0 professor monitorou a atividade enquanto escrevia no quadro uma nuvem de palavras que gravitavam em torno do objeto principal. Esse momento foi importante para a construção de vocabulário, necessário para cumprir as etapas de leitura do projeto de ensino. Alguns exemplos de palavras mais recorrentes foram "dark", "fear", "vampire", "monster", "ghost", "blood", "supernatural", entre outras.

Posteriormente, foram apresentados slides que abordam um conjunto de tópicos relacionados ao tema, tanto na literatura como no cinema. Os alunos acessaram o conteúdo através de imagens e subdivisões textuais, aspectos como ambientação, definições de termos, autores importantes e personagens marcantes. No decorrer da prática, o professor fez uma apresentação física de alguns livros do gênero. Essa exposição foi acompanhada pela análise de elementos contidos nas capas, orelhas e outras informações paratextuais. Além disso, verificou-se uma oportunidade de utilizar técnicas de leitura como skimming e scanning, introduzir novas palavras, discutir alguns conceitos e aprofundar as discussões no universo da ficção de horror/terror. Pensamos que seja importante enfatizar que as etapas de Cosson (2019) não devem ser vistas como blocos separados. Elas podem ser integradas umas às outras, alternando as fases de introdução, leitura e interpretação.

A segunda aula do projeto equivale à etapa de introdução, na qual foi feita apresentação dos autores e das obras. Embora esse estágio represente uma atividade relativamente simples, demanda certos cuidados. Segundo Cosson (2019), a exposição não deve ser uma longa e expositiva aula sobre a vida do escritor. Além disso, a escolha dos textos que serão utilizados como referência deve trilhar a direção da pluralidade e diversidade de autores, obras e gêneros. Entendemos ainda que a escolha compreende uma seleção baseada nos clássicos, mas também abrange a linguagem dinâmica dos filmes, séries e jogos eletrônicos. Nesse sentido, Cosson (2019) salienta que os textos precisam ser curtos, contemporâneos e divertidos, além de contribuir para o ensino do idioma, tanto pelo texto literário e sua linguagem culta, como pela capacidade de comunicação que o cinema proporciona.

Nesse cenário, distribuímos o artigo The evolution of horror in fiction: a brief guide, de Felipe Wasserstein (2017) que, como vimos na seção anterior, quando tratamos sobre as características do 
gênero, introduz autores e obras fundamentais da literatura e do cinema. Com o material em mãos, os estudantes realizaram a leitura e, a partir desta, responderam a exercícios de interpretação propostos, além de elaborarem uma questão. $O$ texto em análise funcionou tanto para cumprir o objetivo da etapa de introdução como de leitura, uma vez que escolhemos o gênero jornalístico como referência teórica. $A$ fase de leitura da obra literária em si, como na proposta de Cosson (2019), ficou para um momento posterior, quando lemos $O$ gato preto (1843), de Edgar Allan Poe.

Como vimos na seção de contextualização, o artigo de Felipe Wasserstein (2017) retoma vários pontos discutidos na primeira aula, além de expor um breve panorama do gênero horror/terror, em que destaca autores, obras e características relevantes para a compreensão da temática do projeto de ensino. Como os temas já haviam sido apresentados na etapa de motivação, o conhecimento prévio contribuiu para que a leitura fosse mais fluida e de melhor entendimento. Sobre o letramento literário, Cosson (2019) ressalta ainda que a leitura deve ter um acompanhamento. Desse modo, o professor supervisionou a assimilação dos estudantes, assim como esclareceu algumas dificuldades relacionadas à compreensão de vocabulário ou mesmo de partes do texto. Na sequência didática, o professor realizou a leitura em voz alta, ressaltando aspectos linguísticos importantes e dando ênfase à pronúncia de determinadas palavras.

Após os dois primeiros estágios, foi aplicado um teste escrito, de modo a verificar o processo de ensino-aprendizagem até o momento. A avaliação foi produzida tendo o artigo de Wasserstein (2017) como referência, utilizando-se de questões interpretativas, de verdadeiro ou falso e de relacionar autores com suas características. Essa prática, assim como as outras avaliações propostas durante a unidade, tem o potencial de diagnosticar tanto o desempenho do aluno como também do professor e da escola. Ao final da unidade, as avaliações foram analisadas criticamente, permitindo correções ou confirmações dos procedimentos avaliativos, dando espaço para manter ou renovar o planejamento.

A segunda parte do planejamento consistiu na exibição de uma sequência de curtas-metragens, intitulados " 25 horror short films we dare you to watch alone tonight"3. Esse foi um dos momentos mais aguardados pelos estudantes no decorrer da unidade, porque além de resultar em alguns sustos e muitos risos, mexeu com os medos primários da audiência. Foi também uma oportunidade de discutirmos produções com baixo orçamento, algumas características do cinema de horror/terror, como ambientação, efeitos sonoros e mudança rápida de câmera.

Tivemos cuidado em selecionar os filmes exibidos dentre os 25 indicados no site, porque acreditamos que determinadas cenas não são apropriadas para serem exibidas no contexto de sala de aula, tendo em vista a faixa etária do público-alvo. A esse respeito, é importante mencionarmos o

${ }^{3}$ Os curtas-metragens podem ser acessados pelo link a seguir: https://www.scoopwhoop.com/inothernews/short-horror-films/ LínguaTec, Instituto Federal de Educação, Ciência e Tecnologia do Rio Grande do Sul, Bento Gonçalves 
raciocínio de Menon (2008), sobre o fato de que, se ninguém gosta de sentir medo, por que a fiç̧ão de horror, mistério e suspense se desdobrou além da literatura? De acordo com o autor, podemos interpretar que, ao invés de constituir uma real ameaça, o universo da ficção de horror e terror nos permite dialogar com os medos de uma maneira segura, uma vez que leva crianças e adultos a pensar mais sobre 0 desconhecido e sobre o destino humano. Apesar disso, escolhemos não mostrar curtas-metragens que contivessem cenas de violência explícita ou que pudessem chocar o público.

Dentre os curtas exibidos, alguns merecem menção especial e serão brevemente analisados nas linhas a seguir. Além disso, discutiremos como algumas dessas atividades foram trabalhadas na sala de aula.

Lights out (2013) e Pictured (2014), ambos do diretor David F. Sandberg e com atuações de Lotta Losten, são curtas que lidam com aparições sobrenaturais. Os filmes são bem estruturados e demonstram domínio sobre os mecanismos do gênero terror, em que o tempo é bem coordenado e a expectativa do medo cresce no telespectador.

2AM- The smiling man (2013) é do diretor Michael Evans e é um dos mais assustadores da lista. O filme tem início com um jovem andando apressadamente em rua escura e deserta, quando de repente percebe que está sendo perseguido por um homem sorridente. É uma história que começa despretensiosamente e tem um fim sinistro.

He dies at the end (2010) é um curta de Damian Mc Carthy Alone, que se passa em um escritório, no qual um homem participa de um estranho questionário online para descobrir como ele vai morrer. Esse filme torna oportuno pausas pontuais ou mesmo uma repetição das cenas, visto que o misterioso assassino faz diversos questionamentos à vítima, por escrito, através da tela de um computador. Esse momento revelou-se apropriado para tratar de questões linguísticas, abordar conceitos como anticlímax, construção da tensão e da ambientação do terror.

O próximo curta da lista é uma animação de terror e fantasia, dirigido e produzido por Rodrigo Blass. Alma (2009) é um filme repleto de uma atmosfera infantil e divertida, e que por outro lado, manifesta mistério e terror enquanto você assiste. 0 curta aborda a noção de "alma" e a possibilidade de uma boneca poder possuí-la. A animação é incrivelmente bem feita e retrata uma dezena de bonecos(as) com variadas expressões (algumas aterrorizantes) e com diferentes estilos e roupas. A música e o som ambiente oferecem uma atmosfera sombria e perturbadora. Ao final da exibição, a discussão envolveu questões relacionadas ao gênero e ao estilo, aos exemplos de "é um curta de horror/terror?", "quais são os principais aspectos?", entre outros.

Além de Alma (2009), outros curtas-metragens da lista apresentam características mais amenas e menos aterrorizantes. Em geral, são filmes que apelam para o lúdico do medo ficcional. Embora 
contenham elementos do horror/terror, há uma evidente suavização das histórias. Outros exemplos que se enquadram nessa temática são Behind closed doors (2009), de Jonny Button, que lida com problemas familiares, e Jack (2010), de Drew Daywalt.

Pensando em amenizar o impacto que a sessão de filmes pode gerar em alguns estudantes, ou para um planejamento com outra faixa etária de público, podemos pensar em obras com particularidades semelhantes, que não causem medo ou repulsa, mas que tragam outros componentes. Tim Burton, por exemplo, tem um repertório de filmes que apresentam aspectos góticos, sombrios e fantasiosos, que demonstram temas bem-humorados ou estilizados, tais como o curta-metragem Frankenweenie (1984). Também há uma refilmagem de 2012, produzida pelo mesmo diretor. Esse é um curta-metragem paródia que presta homenagem ao filme Frankenstein de 1931. Nesse sentido, podemos fazer relações entre a obra original de Mary Shelley, a película de James Whale, da Universal Pictures e o curta de Tim Burton. O tema desenvolvido pode "trazer à tona discussões éticas acerca da tentativa de se criar um ser humano, [...] também levanta o problema daquele que se vê excluído da sociedade" (MENNON, 2008, p. 79).

Outros filmes do mesmo diretor são indicados para desenvolver o planejamento, tais como Edward mãos de tesoura (1990), O estranho mundo de Jack (1993), A lenda do cavaleiro sem cabeça (1999), baseado no clássico conto de Washington Irving, de 1820, e A noiva cadáver (2005). Além disso, há centenas de curtas disponíveis no YouTube que podem alimentar este projeto de ensino.

Ainda nessa perspectiva, as obras literárias e cinematográficas aqui analisadas podem e devem dialogar com outras artes. 0 horror/terror também pode ser encontrado na pintura, como por exemplo, nas ilustrações de Gustave Doré, como as que ilustram A divina comédia, de Dante Alighieri, e o poema O corvo, de Edgar Allan Poe; ou mesmo o famoso quadro Saturno devorando um filho, de Francisco de Goya. Outro tipo de intertextualidade pode ser encontrado nos quadrinhos, tais como, para citar alguns exemplos, John Constantine, de Alan Moore, que aparece nas histórias das séries Monstros do pântano e Hellblazer, e que foram adaptadas para o cinema em 2005; Hellboy, famoso personagem de Mike Mignola, presente em quadrinhos, filmes, animações e jogos eletrônicos desde 1991; e The walking dead (2003-2019), de Robert Kirkman, que também está em outras mídias, como séries para TV, livros e videogames. Em síntese, são muitas possibilidades. Cabe ao professor a escolha de quais obras, personagens e versões produzirão um melhor trabalho. Ao fim da sessão de cinema foi feita a proposta de produção de curtas, como parte das atividades avaliativas da unidade.

A aula seguinte da unidade consistiu em uma dinâmica que envolve filmes e personagens clássicos da literatura e do cinema. A turma foi dividida em grupos, sendo que a cada rodada um componente, de costas para a tela, com papel e lápis, deve descrever os acontecimentos e caracterizar 
o vilão/monstro por escrito. Foram exibidas algumas cenas marcantes do cinema, como o Frankenstein, de 1931, quando ele encontra e brinca com a garota, antes de jogá-la na água; um dos primeiros ataques do filme Tubarão (1975); um trecho de O exorcista (1973) e outras cenas com vampiros e lobisomens. As descrições que mais se aproximaram das cenas reproduzidas marcaram pontos para a equipe. $A$ atividade envolveu uma questão sensorial porque proporcionou que, somente através do som, os estudantes pudessem compreender partes de diálogos e da ambientação.

Durante a segunda parte dessa aula, após a dinâmica com os filmes, fizemos a leitura de uma adaptação do conto $O$ gato preto (1843), de Edgar Allan Poe. Antes de prosseguir, gostaríamos de apontar uma dificuldade na execução da proposta, sobretudo porque a leitura da maioria das obras citadas nesta narrativa de ensino demanda um nível avançado de compreensão do idioma. Por essa razão, selecionamos para este planejamento uma obra adaptada para o público em questão. Nessa perspectiva, o conto selecionado foi retirado da versão The black cat and other stories, da Penguin Readers, direcionada para o público pré-intermediário. Ademais, procuramos seguir as etapas indicadas por Cosson (2019) para o letramento literário e tivemos o cuidado de selecionar um texto curto, que prende a atenção do leitor.

O conto de Poe traz uma riqueza de detalhes e cria uma atmosfera de suspense, mistério e obscuridade. A adaptação é recontada por David Wharry e contém ilustrações e exercícios propostos que contemplam pré-leitura e pós-leitura. As questões abrangem detalhes sobre as ilustrações, vocabulário, tópicos gramaticais e interpretação de texto. $O$ conto foi originalmente publicado em uma edição do Saturday Evening Post, de 19 de agosto de 1843. É narrado por um homem que se encontra preso e que conta toda a história que o fez chegar até lá. A obra funciona como um estudo da psicologia da culpa que o homem tem por suas atitudes maldosas e violentas, causadas principalmente pelo alcoolismo. Como outros autores do gênero, Poe usa uma espécie de terror psicológico em suas obras, suas personagens oscilam entre a lucidez e a loucura, quase sempre cometendo atos infames ou sofrendo de alguma doença. Outro aspecto é que seus contos são sempre narrados na primeira pessoa.

A leitura do conto foi realizada pelo professor, em voz alta, pausadamente. Durante alguns intervalos, foram abordadas características como o uso de figuras de linguagem, o estilo de escrita, vocabulário variado, ambientação e outros aspectos literários. Ressaltamos que esse estágio do planejamento condiz com as etapas de leitura e intepretação, como propostas por Cosson (2019). Por fim, reforçamos que o uso da literatura no ensino de língua inglesa vem sendo discutido com mais frequência e implantado aos poucos, já que traz benefícios não só linguísticos como também culturais.

As duas aulas seguintes da unidade compreenderam preparação e apresentação de seminários. A proposta avaliativa consistiu em apresentações de 15 minutos, em que os estudantes explanaram vida 
e obra de autores do gênero horror/terror. Esse método permitiu que todos se dedicassem um pouco mais à disciplina e interagissem com o conteúdo de uma forma mais prática e como protagonistas. Acreditamos ainda que a escolha pelo tema pode ficar a critério dos alunos. A primeira das duas etapas foi executada em um laboratório de informática, mediante orientação do professor, com o objetivo de que os grupos pudessem pesquisar sobre seus autores escolhidos e produzir os slides que serviram como guias durante a apresentação dos seminários.

Os trabalhos apresentados no ano letivo de 2019 constituíram variada gama de escritores e cineastas. Muitos grupos já tinham em mente o tema de seus seminários, pois conhecem e acompanham os mais novos filmes do gênero e, por razão desse contato, escolheram célebres cineastas como James Wan, Tobe Hooper, Mike Flanagan, Tim Burton, e até mesmo autoras menos conhecidas, como a baiana Gabriela Amaral Almeida. As apresentações continham texto na língua alvo e abordaram aspectos como a importância da obra, contextualização histórica, análise de personagens etc.

$\mathrm{Na}$ etapa seguinte do projeto de ensino foram exibidos os curtas produzidos pelas turmas. Além disso, utilizamos a aula para refletirmos sobre o desenvolvimento da unidade. Os alunos participaram dessa atividade avaliativa de diversas formas, que variaram entre a elaboração de roteiros e diálogos, 0 papel de atuação, construção de legendas, edição e publicação dos vídeos. As produções das turmas no ano de 2019 foram excelentes experiências, porque demonstraram as habilidades que os alunos da atual geração têm com as tecnologias disponíveis para gravar, editar, produzir e legendar pequenos filmes. As turmas produziram curtas-metragens cujos enredos tratavam sobre aparições e sumiços repentinos, com sequências narrativas apropriadas, atuações arrebatadoras, além de divertidos diálogos, todos com uma pitada de humor, porque envolveram aspectos como pronúncia, atuação e do fato se verem reproduzidos na tela. Ressaltamos ainda que essa atividade avaliativa proporciona que os alunos sejam ativos no desenvolvimento do processo de ensino-aprendizagem.

Finalmente, a última aula da unidade constituiu-se do teste de recuperação para aqueles que não atingiram nota mínima. Esta avaliação, assim como o teste escrito, foi baseada no texto The evolution of horror in fiction: a brief guide, de Felipe Wasserstein (2017), que como vimos, foi a principal referência teórica da unidade. Segue no quadro abaixo resumo da sequência didática descrita nesta seção:

\begin{tabular}{|c|c|}
\hline Aula 1 & Apresentação do tema, slides, horror word cloud, levar livros para mostrar; \\
\hline Aula 2 & $\begin{array}{l}\text { Leitura do texto "The evolution of horror in fiction: a brief guide" - } \\
\text { http://thecircular.org/evolution-horror-fiction-brief-guide/; }\end{array}$ \\
\hline Aula 3 & Teste escrito baseado no texto da aula anterior; \\
\hline Aula 4 & $\begin{array}{l}\text { Exibição de curtas da lista "25 horror short films we dare you to watch alone } \\
\text { tonight" - https://www.scoopwhoop.com/inothernews/short-horror-films/; }\end{array}$ \\
\hline Aula 5 & $\begin{array}{l}\text { Divisão de grupos, orientação e preparação dos seminários - Aula no } \\
\text { laboratório de informática; }\end{array}$ \\
\hline Aula 6 & Apresentacão dos seminários; \\
\hline
\end{tabular}

LínguaTec, Instituto Federal de Educação, Ciência e Tecnologia do Rio Grande do Sul, Bento Gonçalves v. 5, n. 2, p. 366-379, nov. 2020. 


\begin{tabular}{|l|l|}
\hline Aula 7 & Brincadeira com cenas de filmes/leitura do conto de Edgar Allan Poe; \\
\hline Aula 8 & Exibição dos curtas; \\
\hline Aula 9 & Teste de recuperação. \\
\hline
\end{tabular}

Quadro 1. Quadro-resumo da sequência didática.

Fonte: $O$ Autor.

\section{Considerações finais}

Procuramos apresentar neste trabalho alguns modos de utilizar a literatura e o cinema de horror/terror para o ensino de inglês no Ensino Médio. Vimos também como esse tipo de ficção pode desenvolver a reflexão crítica, o autoconhecimento e de como podemos trabalhar em paralelo com outras áreas do conhecimento.

A escolha do tema e dos textos utilizados no desenvolvimento do projeto levou em consideração o que propõe Rildo Cosson (2019), que explica como as possibilidades são diversificadas e dependem da turma, dos materiais escolhidos e dos objetivos do professor. Ao levar essas particularidades em consideração, possibilitamos ao aluno um processo coerente, com o trabalho sistematizado. Desse modo, percebemos que muitos temas podem ser discutidos através das leituras e análises propostas.

Tratamos ainda sobre as definições e particularidades do horror/terror, além de um breve panorama histórico, apontando características e produções significativas do gênero. Ademais, procuramos desconstruir alguns preconceitos e críticas que rondam as literaturas de horror e terror, e buscamos maneiras de levá-las para a sala de aula, de forma a aprimorar o estudo de língua estrangeira e estimular a leitura.

Com base na teoria desenvolvida por Cosson (2019), é interessante observar ainda que, para que 0 aluno tenha prazer na leitura, ele precisa passar pelo letramento literário. A escola tem papel fundamental nesse processo e talvez seja ela, de fato, a principal responsável pela formação e consolidação de alunos leitores.

Por fim, gostaríamos ainda de destacar algumas razões importantes para o uso do texto literário em sala de aula, amparadas por Lazar (2004 apud CORCHS, 2006), sobretudo quando a autora cita motivações para o uso de textos literários no ensino de língua inglesa, desde o fato de que ajudam a entender outras culturas, podem encorajar os estudantes a expor suas opiniões e sentimentos, além de estimular a aquisição da língua e desenvolver a capacidade de interpretação. Podemos pensar, ainda segundo Lazar (2004), que constituem material autêntico, podem ser encontrados em vários níveis e de que são motivadores para os alunos. Pelas experiências adquiridas durante o desenvolvimento do projeto aqui descrito, podemos perceber na prática esses e outros aspectos quando utilizamos o texto literário para o ensino-aprendizagem de uma língua estrangeira.

LínguaTec, Instituto Federal de Educação, Ciência e Tecnologia do Rio Grande do Sul, Bento Gonçalves 


\section{Referências}

BRASIL, Ministério da Educação e Cultura/Secretaria de Educação Básica. Orientações curriculares nacionais: linguagens, códigos e suas tecnologias. Brasília: MEC/SEB, 2006. v. 1. Disponível em: http://portal.mec.gov.br/seb/arquivos/pdf/book_volume_01_internet.pdf. Acesso em: 27 jul. 2020.

CORCHS, Margaret. O uso de textos literários no ensino de língua inglesa. Universidade Federal do Ceará. Fortaleza, 2006.

COSSON, Rildo. Letramento literário: teoria e prática. São Paulo: Contexto, 2019.

LIMA, D. C. (Org.) Ensino e aprendizagem de língua inglesa: conversas com especialistas. São Paulo: Parábola Editorial, 2009.

MENON, Maurício César. A narrativa de mistério/suspense, terror/horror no ensino médio: ponderações e esclarecimentos. In: OLIVEIRA, Vanderleia da Silva. Educação literária em foco: entre teorias e práticas. Universidade Estadual do Norte do Paraná. Cornélio Procópio: Campus de Cornélio Procópio, 2008.

PAIVA, Vera Lucia Menezes de Oliveira e. Ensino de língua inglesa no ensino médio: teoria e prática. São Paulo: Edições SM, 2012.

POE, Edgar Allan. The black cat and other stories. Penguin Readers (Level 3 - Pre-Intermediate) England: Pearson Education Limited, 1991.

WASSERSTEIN, Felipe. The evolution of horror in fiction: a brief guide. The Circular, 2017. Disponivel em: <http://thecircular.org/evolution-horror-fiction-brief-guide/>. Acesso em: 04 abr. 2019.

Data de submissão: 21/09/2020. Data de aprovação: 26/10/2020. 